\title{
Imperfectivity and complete events
}

\begin{abstract}
Atle Grønn
Imperfectivity is cross-linguistically associated with the subinterval property and a modal component induced by the famous 'imperfective paradox'. These properties arguably hold for both the progressive and habitual-iterative readings. However, both in Romance and Slavic, the imperfective may also refer to complete events instantiated in the world of evaluation: the so-called Imparfait narratif in French and the Factual Imperfective in Russian.

I propose an analysis of viewpoint aspect in terms of temporal inclusion relations between the event time and the assertion time. Importantly, however, the source of the two complete event readings in question are quite different inasmuch as the Russian imperfective is unmarked and is used whenever the marked perfective aspect is inappropriate, while the French Imparfait is marked. This means that the French Imparfait retains its meaning of contemporaneity even when it has a complete event interpretation.
\end{abstract}

\section{Introduction ${ }^{1}$}

The category of viewpoint aspect (Smith 1997) - that is, the opposition between perfective (PF) and imperfective (IPF) verb forms - plays an important role in language families such as Slavic and Romance. Imperfectivity is cross-linguistically associated with the subinterval property (atelicity), which is characteristic of both the progressive and habitual-iterative readings. If a sentence, whose main verbal predicate is marked with IPF, is true of a certain temporal interval, then the same sentence is also true of subparts of this interval.

However, both in Slavic and Romance, IPF may also refer to complete events in which case this inference does not go through. If a complete event of the type of the VP holds at a time $t$, it is not necessarily true that a complete event of the same type also holds at an arbitrary subinterval $t^{\prime}$ of $t$. What are the implications of these puzzling complete event readings for the universal notion of imperfectivity?

1. I would like to thank Nikolaj Vazov and the audiences of Gothenburg 2004 and Kjell Johan Sæbø's circle of theoretical linguistics (Oslo 2005) for valuable comments at various stages of this work. 
In this paper I propose an analysis couched in event semantics of the Factual Imperfective (obshchefakticheskoe znachenie) in Russian and Imparfait narratif in French which shows that the two complete event readings in question are quite idiosyncratic. A more fine-grained analysis reveals their different semantic properties, explaining why these two complete event readings are not attested in the same range of contexts. The point is that these specific interpretations of the imperfective viewpoint arise in competition with other tense-aspect grams in the verbal system, and the role of IPF in Russian is very different from IPF in French, inasmuch as only the latter is marked and therefore expected to get a uniform interpretation.

\section{The data}

The most important subsets of the complete event readings of IPF in Russian are labelled 'existential IPF' (ex. 1) and 'presuppositional IPF' (ex. 2) in (Grønn 2004).

(1) Vanja chital Vojnu i mir.

Vanja read.IPF.PAST War and peace

Vanja has read War and Peace.

(2) A: Krasivo ukrasili elku. beautifully decorate.PF.PAST.PL spruce-ACC

A: They decorated the Christmas tree beautifully.

B: Kto ukrashal? (from Rassudova) Who.NOM decorate.IPF.PAST

B: Who decorated it?

A semantic representation of example (1) should encode the speaker's assertion that there exists a complete past event of Vanja's reading War and Peace. The imperfective verb in speaker B's utterance in the discourse of (2) also conveys the fact that there exists a complete past event of the type denoted by the VP. However, in this case the existence of the event is not asserted, but presupposed since it is already entailed in the input context through speaker A's utterance containing the perfective verb ukrasili. In the dynamic two-dimensional representational format of Discourse Representation Theory (Kamp, 2001), the difference between (1) and (2) is primarily captured by declaring the verb's event argument in the assertoric and presuppositional component, respectively.

The complete event interpretation of IPF in French is often referred to as Imparfait narratif, reflecting the fact that it typically occurs in contexts of narrative progression, as witnessed by examples such as (3) below:

(3) A huit heures, les voleurs entraient imparfait $_{\text {dans la banque, ils discutaient }}$ impar-

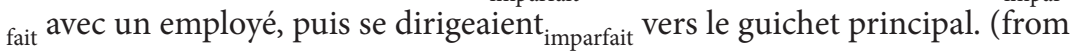
Jayez 1999) 
At eight, the robbers entered the bank. They discussed with a clerk and then they moved towards the main desk.

This usage of telic VPs with the imperfective viewpoint (entraient - 'entered') is completely ruled out in Russian, where the factual IPF can never move the narration forward. In Russian, the PF occurs happily in contexts of narrative progression and the factual IPF is effectively blocked in this environment. Indeed, the complete event reading of the factual IPF is compatible with event anaphora, as we saw in example (2) above, but IPF in Russian cannot be used to assert the existence of a complete event at a punctual or contextually given interval, as in the French case above. Hence, phenomena such as temporal anchoring and temporal anaphora interact quite differently with the imperfective viewpoint in French compared to Russian.

Furthermore, we note that Imparfait narratif combines with Vendlerian achievements, such as entrer, while the factual IPF applies to accomplishments like chitat' Vojnu i mir or ukrashat' elku. This distinction in the telic properties of the VPs being input to the imperfective operators in the two languages under discussion is not merely a coincidence, as we will see in section 5 .

\section{Diachronic pressure towards a binary opposition}

The tense-aspect systems of Russian and French have developed quite differently from a common Indo-European source. While French partly retains the original inflectional category Imperfect:Aorist, Russian, like other Slavic languages, is now equipped with a more derivational like aspectual category Perfective:Imperfective (See Bermel (1997) for a diachronic analysis of the emergence Russian aspect). Interestingly, both contemporary French and Russian have the formal means to express a complete/incomplete event opposition, and, furthermore, both French and Russian will eventually end up with a pure binary opposition between two members of the aspectual category in past tense, cf. table 1 and 2.

Table 1. First round. Inventory of past tense-aspect forms of the verb 'to read' (1sG.)

\begin{tabular}{ll}
\hline Written/earlier French & Old Church Slavic \\
\hline Imparfait (lisais) & Imperfect (chitaakh") \\
Passé simple (lus) & Aorist (chitakh") \\
Passé composé (ai lu) & Perfect (jesm' chital”) \\
\hline
\end{tabular}


Table 2. Second round. Inventory of past tense-aspect forms of the verb 'to read' (1sG.)

\begin{tabular}{ll}
\hline Spoken/modern French & Russian \\
\hline Imparfait (lisais) & Imperfective (chital) \\
Passé composé (ai lu) & Perfective (prochital) \\
\hline
\end{tabular}

The emerging simplified picture of a binary opposition in table 2 is not witnessed in some other Slavic and Romance languages, e.g. Bulgarian and Portuguese, which display a greater variety of tense-aspect grams, and therefore also a somewhat different set of usages of the imperfective viewpoint. The hypothesis to be explored here is that the more or less idiosyncratic complete event readings of IPF in Russian and French should be understood in light of the competition between two forms in a closed system. I will claim that the ways in which the aspectual opposition is morpho-syntactically expressed in table 2 largely determine the use of imperfectivity with complete event readings in the languages under consideration. This implies that the analysis presented here does not straightforwardly extend to cover imperfective complete event interpretations in, say, Bulgarian, which does not reduce to a clear-cut aspectual opposition, but where a derivational (Slavic) system coexists with an inflectional (Romance) system and furthermore interacts with overt manifestations of perfect tenses.

\section{Key ingredients of the analysis}

\subsection{Markedness}

The analysis to be presented restores some traditional insights, notably concerning the rather problematic notion of markedness. The Jakobsonian idea of applying markedness theory to grammatical categories such as aspect has a long history in Slavic linguistics, but it has lately lost in popularity. However, with the fast-growing framework of Bidirectional Optimality Theory, that is OT from both the hearer (interpretation) and speaker (production) perspective (Blutner 2000), we finally have the tools to implement markedness theory in a formal analysis. Importantly, Bidirectional OT is primarily a diachronic theory, which can explain why certain form-meaning pairs are optimal in an evolutionary setting both for the hearer and speaker. It is often unreasonable to expect the discourse participants to calculate the optimal form-meaning pairs in online communication (synchronically), since this mental process can be utterly complex (the speaker has to consider a set of forms; the hearer has to consider a set of interpretations for each form; and both have to consider a possibly large number of form-meaning pairs in order to arrive at the optimal outcome). However, speakers and hearers learn from (mis-)communication and eventually, hence diachronically, 
agree on the optimal form-meaning combinations. ${ }^{2}$ Furthermore, markedness theory can serve as a guide for the semanticist: Since it is well-established that PF is marked in Russian - viewpoint aspect in Russian is primarily a grammaticalisation of telicity expressed through prefixation - the analysis should start with an invariant definition of perfectivity, and the range of usages of the unmarked IPF should follow from competition between the marked and the unmarked forms.

In French, the picture is the opposite inasmuch as the perfective like aorist (Passé simple) is historically the unmarked form, cf. (Breu 1998). According to the traditional view of French aspectologists like Guillaume, Passé simple stands outside the complete/incomplete event opposition (Jayez 1999). I will therefore propose an explicit semantic interpretation of Imparfait, which is expected to have an invariant meaning due to its markedness.

Note that in contemporary spoken French the marked member of the original aspectual opposition has proven more viable than the unmarked. The presence of IPF and the morphologically orthogonal composite perfect has made the aorist (Passé simple) superfluous in the following way: Whenever Passé simple was used historically with atelic predicates it can easily be replaced by IPF, as in (4) below:

(4) Jean travailla ${ }_{\text {passé simple }}$ beaucoup. $\Rightarrow$ Jean travaillait imparfait $_{\text {beaucoup. }}$ John worked a lot.

In many cases of Passé simple being applied to telic predicates with a complete event interpretation, Passé composé enters the scene, since perfect tenses by default have a complete event interpretation with telic predicates, cf. (Bohnemeyer and Swift 2004). However, the possibility of Imparfait narratif in certain aoristic contexts blurs the straightforward correlation between Passé simple and Passé composé, since it shows that also Imparfait may, in the right context, function on the traditional domain of Passé simple. ${ }^{3}$

In Russian, like in French, we have a neat aspectual opposition in past tense. However, in Russian the unmarked form is in no danger of disappearing. The imperfective viewpoint is simply necessary to maintain the aspectual opposition, since no other aspectually loaded grams are available in the grammar.

2. See Grønn (2008) for a bidirectional OT approach to Russian aspect, and Grønn (2007) for a purely diachronic view on the emergence of Russian aspect.

3. Breu (1998), like the present paper, compares the tense-aspect systems of Slavic and Romance from the perspective of markedness theory. However, in view of Imparfait narratif, Breu is wrong when he claims that in a translation of viewpoint aspects from Romance to Slavic (or the other way) the marked aspect of the source language, say French, always corresponds to the same unmarked form in the target language, say Russian. Breu thus predicts that the marked Imparfait translates into the unmarked IPF in Russian. This cannot be correct since the marked Imparfait narratif in French always corresponds to the marked PF in Russian. On the other hand, Breu is right when he points out that the unmarked form of the source language does not tell us which form to choose in the target language (Breu 1998: 95). 
The fact that morphologically composite perfect tenses disappeared in Russian was related to a more general loss of the copula, a process which was orthogonal to the emergence of the new PF:IPF dichotomy. As shown in (Grønn 2004), the functions of perfect tenses may still be rendered in contemporary Russian by simple past forms of perfective and imperfective verbs. In the case of present perfect readings, this is rather trivial since the grams present perfect and simple past are truth-conditionally equivalent (with telic predicates). The difference is merely that a simple past makes use of the utterance time as a default evaluation time, while a present perfect explicitly designates the utterance time as the time for which the resultant state of the event holds. ${ }^{4}$

\subsection{Viewpoint aspect in Russian as temporal relations}

Following contemporary approaches to viewpoint aspect - in the spirit of (Klein 1995) - I treat aspect as a temporal phenomenon which interacts with tense through Reichenbachian temporal parameters. The complete event reading of PF in Russian can be captured by the inclusion relation $e \subset t$, saying that the run time of the event $e$ is properly included in the assertion time $t$. The latter notion refers to the time interval on which the speaker focuses, an interval which is typically denoted by a temporal adverbial, as in (5):

\section{(5) Chasov v shest'vechera poobedali. (Internet) \\ Hours.gen at six evening.Gen dine.PF.PAST.PLUR \\ We had dinner around six p.m.}

A semantic representation for this sentence should contain a condition like $e \subset t$, where $e$ represents the event of eating dinner, while $t$ equals the frame time of approximately one hour denoted by the adverbial. In absence of temporal adverbials or context times, the assertion time parameter is merely restricted by past tense, and then equals 'the whole past preceding the current evaluation time. ${ }^{5}$ Note that the Reichenbachian reference time parameter is split into the assertion time and the evaluation time, and it is thereby given a more empirical foundation inasmuch as the assertion time gets its value from overtly expressed temporal adverbials and tenses.

4. The case of covert past perfect readings in Russian, however, is much more complicated. See Grønn (2004) for a thorough discussion of relative past tense (for instance in complements of verba dicendi).

5. The evaluation time parameter will here be represented by the distinguished variable $t_{0}$, which equals the utterance time whenever it occurs free in the semantic derivation, cf. von Stechow (1995). 
The progressive reading of IPF can be rendered through the opposite inclusion relation, that is, $t \subset e$. Hence, we have the tools to capture the fundamental aspectual opposition between (5) and (6):

(6) My obedali

we-NOM dine.IPF.PAST

kogda u moego druga proizoshel pristup. (Internet)

when with my friend-GEN happen-PF-PAST attack-NOM

We were having dinner, when my friend had a heart attack.

In example (6), the assertion time $t$, which corresponds to the time denoted by the temporal adverbial (the kogda/when-clause), is properly included in the time of the event of having dinner. In other words, the speaker merely focuses on a proper subpart of the eating event, and the aspectual configuration should only license an inference to an incomplete event of having dinner. For all we know, the dinner event may have been interrupted in the real world (the imperfective paradox).

In virtue of being unmarked, IPF in Russian may also refer to complete events, as in example (7):

(7) $\mathrm{Ty}$

Ty segodnja obedal $\quad v$ restorane! (Internet)
You.NOM today dine.IPF.PAST in restaurant.LOC
You had dinner in a restaurant today!

In (7), we get an 'existential IPF' interpretation, that is, the speaker asserts the existence of a complete event of having dinner within the proper subinterval of segodnja ('today') which precedes the utterance time.

Thus, the unmarked imperfective is compatible with totally opposite inclusion relations, and it seems impossible to find an invariant meaning of this viewpoint. This is in fact also what markedness theory suggests: There is no such thing as the meaning of IPF in Russian since the imperfective viewpoint merely amounts to the non-use of PF. An imperfective sentence such as (8) below can therefore be considered as underspecified without further context, but will in practice (i.e. given a specific context) get one out of three interpretations, as indicated in the English translations:

(8) Ja obedal.

I.NOM dine-IPF.PAST

I was having dinner. (at some particular time)

I used to have dinner. (regularly)

I have had dinner. (today) 
In the semantics proper, what we should retain from the discussion above is the invariant analysis accorded to PF, which can be spelled out as follows in a compositional version of Discourse Representation Theory:

(9) Perfective aspect in Russian $\Rightarrow$

$\lambda P \lambda t[e \mid P(e), e \subset t]$

The perfective operator takes a set of events $P$ (a tense- and aspectless VP) as input and returns a set of assertion times $t$ as output. The aspectual operator contributes to the declaration (existential quantification) of the event variable $e$ of type $P$ and further asserts that $e$ is properly included in the assertion time $t$. Later in the derivation, the value of $t$ will be provided by the 'tense branch'. Hence, tense is assumed to have scope over viewpoint aspect at the syntax-semantics interface.

In section 6, I will return to the issue of how the Russian IPF, given the right context, can receive a complete event interpretation in competition with PF.

\section{A semantics for IPF in French}

I will now turn to the French aspectual system, which requires an explicit semantics for the marked form Imparfait.

\subsection{An anaphoric/presuppositional past tense}

As argued in the previous section, aspect is a temporal phenomenon, which interacts closely with tense. However, the syntax-semantics interface appears to be somewhat different in Russian and French. In Russian, viewpoint aspect (e.g. the perfective prefix $p o-$ ) is assumed to be located below tense (e.g. the past tense morpheme $l$ ) in the syntactic input to the semantic interpretation. If we respect the surface morpho-syntax of French, we have to treat Imparfait (the suffix -ai- in 'lisait') as a marker of both aspect and past tense. This implies that the logical type of Imparfait in French must be different from that of aspectual operators in Russian: While an aspectual operator in Russian is a function from predicates of events to predicates of times, the French Imparfait is a function from predicates/sets of events to (dynamic) truth values.

Thus, in the compositional semantics, when Imparfait applies to the VP (an aspect- and tenseless sentence radical), we end up with an expression which contains information pertaining both to tense and aspect. Nevertheless, a sentence with the French Imparfait is still in need of further temporal anchoring in the context:

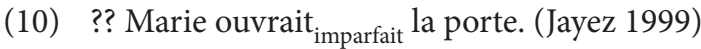
Mary was opening/opened the door. 
I will argue that examples like (10) are infelicitous out of context because of a temporal presupposition of IPF in French. The Imparfait is not a self-sufficient past tense, but requires anchoring to a salient past time. This past time interval can be provided anaphorically (intersententially) or through the presence of temporal adverbials (intrasententially). This observation points to a significant difference between Imparfait in French and a past IPF in Russian.

In this respect, there is a connection between narrative progression, characteristic of Imparfait narratif but unavailable for the Russian Factual IPF, and anaphoricity: The French IPF picks up a contextually salient time provided by the preceding event and moves the narration forward. At the same time, given our uniform treatment of Imparfait, this anaphoricity effect is not restricted to Imparfait narrative. As noted by Smith, there is a link between anaphoricity and imperfectivity tout court:

More generally, sentences with imperfective viewpoints are often dependent on other information in the manner typical of anaphora [...] The partial information given by imperfectives, and the fact that they are frequently used for backgrounding, conspire to produce this effect. (Smith 1997: 90).

Smith certainly has the incomplete event reading (progressivity) in mind, but what is the exact semantic contribution of the French IPF? As mentioned above, the answer to this question must relate to different parameters of temporality since Imparfait is both a past tense and an aspect. Concerning the tense part, I propose a presuppositional treatment, such that the contribution of past tense amounts to presupposing that the assertion time is located prior to the current evaluation time: $t<t_{0}$, cf. the approach to tense semantics in (Heim 1994). In our dynamic DRT-framework, the semantic representation in (11) below is split into an assertoric part and a presuppositional part (Kamp 2001). Accordingly, the condition relating to past tense belongs to the latter, which is marked with the label 'Presupposition'.

\subsection{The inclusion relation}

More challenging is the question of which aspectual configuration should be accorded to Imparfait. Importantly, the imperfective viewpoint in French, as a marked verb form, should get a uniform interpretation, like PF in Russian.

Given the characteristic atelic properties of imperfectivity, the configuration $t \subset e$ (as in the Russian sentence (6) above) is a natural candidate, but, obviously, this proper inclusion relation cannot capture the complete event interpretation of Imparfait narratif. This simple empirical fact represents a serious problem for most previous uniform treatments in formal semantics of the French IPF. For instance, in the classical DRT-tradition, following the important work of (Kamp and Rohrer 1983), Imparfait is treated as a kind of stativiser, which only produces atelic interpretations.

At the same time, the perfective inclusion relation $e \subset t$ clearly runs afoul of the Hauptbedeutung of IPF, that is, the progressive. This leaves us with the configuration 
$t \subseteq e$, where $t=e$ is the extreme case of Imparfait narratif, cf. similar considerations in (Jayez 1998). I therefore propose, in a compositional framework, the following uniform analysis of Imparfait, which solves the paradox of coexisting complete and incomplete event interpretations:

(11) Imparfait in French (preliminary version) $\Rightarrow$ Assertion: $\lambda P[e \mid P w(e), t \subseteq e]$ Presupposition: $\left[t \mid t<t_{0}\right]$

The progressive reading follows straightforwardly from (11) since the configuration $t \subseteq e$ allows for the assertion time to only focus on a proper subpart of the event. Note that the modality of the progressive and habitual-iterative readings - the notorious imperfective paradox - requires manipulation of the world index $w$, an issue which will not be dealt with here. ${ }^{6}$

Of course, the imperfective viewpoint in French is not a pure progressive marker (unlike the periphrastic construction être en train de), but it still encodes contemporaneity. Indeed, concerning Imparfait narratif, the representation in (11) captures an important intuition among French semanticists:

The [assertion time] is viewed as spanning the whole event [...] but not beyond [...], whence the peculiar flavour of the narrative Imparfait: one follows completely some eventuality, then shifts to the next one, etc. (Jayez 1999)

This is exactly what we get if we assume that the complete event interpretation of IPF in French amounts to the aspectual configuration $t=e$.

\subsection{The assertion time}

This neo-Reichenbachian analysis puts considerable restrictions on the size of $t$ in the representation of IPF, and it can therefore explain why Imparfait narratif is ruled out in the main clause of contexts such as (12), where Passé composé has to be used:

(12) Après que Marie est arrivée ${ }_{\text {passé composé Paul est parti }}$ passé composé (??partait $\left.{ }_{\text {imparfait }}\right)$.

After Mary came, Paul left.

The temporal clause après que Marie est arrivée denotes an interval which spans from Mary's arrival to an infinite future. Without any further restrictions, this interval is not a candidate for the value of $t$ in the condition $t \subseteq e$. Such a big interval cannot possibly equal (or be included in) the temporal trace of the event argument. On the contrary, this temporal frame is ideally suited for entering the inclusion relation $e \subset t$ of Passé composé. Perfect tenses, like Passé composé in French, prototypically combine with big, indefinite assertion times, which easily include a complete event of the type denoted by

6. See Ferreira (2005) for a recent treatment of imperfectivity and modality. 
the VP.7 Of course, Passé composé is also restricted to past tense contexts, but this should naturally follow from a proper treatment of the morpho-syntax- semantics interface, where the present tense auxiliary est further delimits the interval denoted by the "après-clause" by establishing a right boundary (= the utterance time) of the assertion time interval.

Contrary to (10) and (12), an appropriate context for the narrative IPF is the following, where the value of $t$ is clearly identifiable and of the right size:

(13) Quelques minutes plus tard, Pierre et Bruno apparaissaient imparfait $_{\text {dans un }}$ panache de poussière, slalomant entre les croissants de dunes à plus de 100 $\mathrm{km} / \mathrm{h}$ devant le vieillard hébété. (internet)

A couple of minutes later, Pierre and Bruno could be seen to emerge (were emerging) out of a cloud of dust, slaloming among the dunes at more than 100 $\mathrm{km} / \mathrm{h}$ before a dazed old man.

The overt temporal adverbial in (13) supersedes the need for a context time and invites the presupposition of past tense to be verified intrasententially, i.e. by the sentence itself. Thus, the variable $t$ in the presupposition is unified with the interval denoted by the adverbial quelques minutes plus tard - 'a couple of minutes later'.

There is naturally a complementary distribution between the two sources of presupposition resolution for past tense. In the presence of a temporal adverbial which explicitly provides the value of the assertion time, there is in general no need to invoke covert context times. ${ }^{8}$ This being said, the adverbial quelques minutes plus tard in (13) displays an interesting mixture of intersentential and intrasentential presupposition verification with the anaphoric element plus tard.

\subsection{The divisibility constraint}

There is still one piece missing: the question of why complete event readings of IPF in Romance predominantly occur with Vendlerian achievements, that is, predicates

7. This feature of the perfect is reminiscent of the kind of complete event interpretation of IPF in Russian which I refer to as the 'existential Ipf'. The Russian IPF thereby represents the opposite picture of what we observe with Imparfait narratif in French, inasmuch as the former typically combines with a big, indefinite assertion time within which the event in question is properly included, cf. the 'life time effect' of Vanja's having read 'War and Peace' in example (1). This feature of the existential Ipf in Russian follows from competition with PF, which is characterised by the property of 'definite temporal anchoring'.

8. Perfect tenses, like Passé composé, prototypically occur in contexts where no context times or overtly expressed frame times are needed. In the temporal calculus developed in (Grønn 2004), the default 'all time' (represented by the distinguished variable $t_{\propto}$ ) is invoked for these cases. This interval is further restricted by past tense to produce the interval 'all time before the current evaluation time. Even if we allow for this default interpretation in the temporal system, it is not relevant for Imparfait, since conditions such as $t_{\propto} \subseteq e$ or $t_{\infty}<t_{0}$ do not make sense. 
which only consist of a culmination. For French, this correlation between punctual Aktionsarten and the narrative reading of IPF has recently been confirmed in the survey of (Hobæk Haff 2005).

One could argue that in order to obtain the configuration $t=e$, the intervals of both $t$ and $e$ should both be conceptualised as punctual. But this is apparently not quite what is going on: French informants (and aspectologists) rather emphasise the opposite idea, viz. IPF zooms in on the whole event and produces a stretching effect which in a certain sense cancels the inherent punctuality of achievements.

In order to capture the data and these judgments, I will argue that the imperfective operator in French comes with a sortal condition requiring the input VP to satisfy the property of divisibility (i.e. if an event $e$ of type $P$ holds at $t$, there exists a proper subpart $t^{\prime} \subset t$, such that an event $e^{\prime}$ also of type $P$ holds at $\left.t^{\prime}\right)$. The final version of the French IPF then looks like this:

(11') Imparfait in French (final version) $\Rightarrow$

Assertion: $\lambda P[e \mid P w(e), t \subseteq e]$ Presupposition: $\left[t \mid t<t_{0}\right]$

i. if $P$ satisfies divisibility

ii. undefined otherwise

This additional condition explains, for instance, why Imparfait gets only a coerced group interpretation with semelfactives:

(14) Jean frappait ${ }_{\text {imparfait }}$ à la porte.

John knocked on the door.

Due to the subinterval property (here: the constraint on divisibility), IPF in examples like (14) cannot refer to a single complete event of knocking on the door. The predicate must be interpreted as referring to a group of knocking events. What, then, happens with punctual achievement predicates like entrer in (3) and apparaître in (13)?

Like the semelfactive in (14), achievement predicates must be coerced due to the sortal condition on the imperfective. For achievements this coercion typically results in a complex event predicate which includes the preparatory process preceding the culmination. There may be many such complex event predicates (e.g. all the possible ways in which Pierre and Bruno could emerge out of a cloud of dust in (13)). For some of these event predicates $P 1, P 2, P 3$ etc. the events satisfying, say, $P 1$ stand in a proper subpart relation with the events of type $P 2$. In this way, the divisibility constraint of Imparfait is satisfied through coercion.

It thus seems that achievement predicates become acceptable with a complete event interpretation of IPF when they are conceived of as more complex "accomplishments". Why, then, are true accomplishments ruled out (or marginal) with a narrative complete event reading of Imparfait? Indeed, it is not clear whether this restriction is absolute. For the Italian Imperfetto, Bonomi (2004) claims that although achievements are clearly preferred in the complete event interpretation, accomplishments may be possible, as well. Concerning the French IPF, in example (3) above - from Jayez (1999) 
- the achievement predicate entraient is followed by the activity/accomplishment discutaient avec and the accomplishment se dirigeaient vers. Interestingly, however, my informants seem to prefer Passé simple or Passé compose for the two last VPs.

The suggestion I want to make here is that accomplishments (and activities) already contain a preparatory process, which satisfies the divisibility constraint, and therefore favour an 'incomplete event interpretation'. In other words, when the imperfective viewpoint combines with a predicate of the accomplishment type, it typically zooms directly in on the preparatory phase leaving the culmination part out of focus. This option is conceptually simpler than the alternative, which would be to coerce the accomplishment into a complex event predicate which includes the end point and still satisfies the divisibility constraint.

\section{Markedness, competition and pragmatic strengthening}

Given the semantics accorded above to the marked PF in Russian and the marked IPF in French, I briefly return in this section to the issue of markedness and the interaction of tense-aspect grams in the verbal system.

\subsection{Competition in Russian}

The Factual IPF, that is, the form-meaning pair $<\mathrm{IPF}$, complete event $>$, is expected to be blocked both from the point of view of production and interpretation. There is a better form for expressing complete events (PF), and there is a better interpretation of IPF (the progressive/processual reading). Still, the data provided above suggests that blocking does not leave this problematic form-meaning pair unemployed in Russian. In optimality theoretic terms, we get what is known as partial blocking (and also deblocking), cf. Grønn (2008).

What the complete event readings of the Factual IPF have in common, is that they occur in contexts where the hearer is not misguided by the use of IPF. In the case of existential IPF (cf. ex. 1), the assertion time is big and indefinite (all time preceding the utterance time), which effectively excludes a progressive interpretation. Hence, if there is no particular focus on the result of the event, the speaker sees no reason not to use the unmarked and more economic IPF. A similar kind of reasoning applies to the presuppositional IPF in examples like (2) above, where IPF is used with event anaphora. Since a complete event of the right kind is already given in (entailed by) the input context, no misunderstanding can arise from the use of the unmarked IPF. The unmarked status of the imperfective viewpoint in Russian is therefore the crucial factor which allows the Factual IPF to reappear on the scene and become the winner in a second round optimisation. 
The pervasive competition between PF and IPF leads to pragmatic strengthening and in some cases rather surprising implicatures:

[T] he unemployed form may soon find a new job, generally expressing something closely related to but subtly different from the canonical interpretation that one might have expected. (Beaver and Lee, 2003: 140)

These phenomena are well-known from text-books on Russian aspect. Here, I restrict myself to one example: the convention of annulled result (dvunapravlennoe znachenie) associated with IPF in the following minimal pair:

(15)

\begin{tabular}{|c|c|c|c|}
\hline Vanja & priekhal & v Moskvu & na proshloj nedele \\
\hline Vanja.NOM & come.PF.PAST & to Moscow-ACC & in last week.LOC \\
\hline
\end{tabular}

(15’) Vanja priezzhal ${ }_{\text {IPF-past }} \mathrm{v}$ Moskvu na proshloj nedele (\#i ostanetsja do zavtra). Vanja came to Moscow last week (\#and will stay until tomorrow).

When the lexically encoded result state following the event holds at the utterance time, PF must be used as in (15). IPF, as in (15'), gets the opposite interpretation: The result state is cancelled, hence the agent must have left Moscow at some point prior to the utterance time.

Such implicatures arise because of the tight competition between two members of a grammatical category. At different levels of optimisation, we get a polarisation of the interpretations accorded to the two aspectual competitors.

\subsection{Competition in French}

The French case is perhaps more tricky to capture in terms of a binary competition since the category of viewpoint aspect in contemporary French belongs to an intermediate phase, for which it would be an idealisation to say that Passé simple has disappeared, although the form is clearly declining. The two stages of the evolution of the tense-aspect system in French referred to in section 3 are therefore coexisting in some narrative texts, where we find both the "old" Passé simple and the "new" Imparfait narratif with complete event interpretations in narrative progression, cf. example (16):

(16) Maigret reprit ${ }_{\text {passé simple }}$ la petite auto noire et, quelques minutes plus tard, il pénétrait $_{\text {imparfait (narratif) }}$ dans la brasserie de la place de la République. (from Hobæk Haff)

Maigret once more took the little black car, and a few minutes later he entered the café at the Republic square. 
Still, the French system is clearly developing into a pure aspectual opposition in past tense between Imparfait and Passé composé, cf. the two different historical stages in table 3 and 4 .

Table 3. Tense-aspect grams in early/written French

\begin{tabular}{lccc}
\hline Form/meaning & $t \subseteq e$ & $e \subseteq t$ & explicit reference to $t_{0}$ \\
\hline Imparfait & $\sqrt{ }$ & $!^{*}$ & $!^{*}$ \\
Passé simple & $\sqrt{ }$ & $\sqrt{ }$ & $!^{*}$ \\
Passé composé & $!^{*}$ & $\sqrt{ }$ & $\sqrt{ }$ \\
\hline
\end{tabular}

Table 4. Tense-aspect grams in modern/spoken French

\begin{tabular}{lccc}
\hline Form/meaning & $t \subseteq e$ & $e \subseteq t$ & explicit reference to $t_{0}$ \\
\hline Imparfait & $\sqrt{ }$ & $!^{*}$ & $!^{*}$ \\
Passé composé & $\sqrt{ }$ & $\sqrt{ }$ & $\sqrt{ }$ \\
\hline
\end{tabular}

In the first round (cf. table 3), Imparfait, as the marked aspect, is accorded the semantics familiar from section 5. Passé simple is the aspectually unmarked past tense, and is in principle neutral with respect to the complete/incomplete event distinction. ${ }^{9}$ On the other hand, as a pure simple past, Passé simple does not explicitly designate the utter-

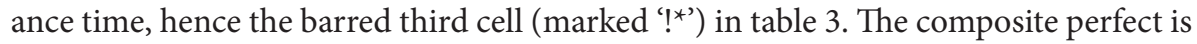
naturally the winner in case of temporal relevance of the utterance time parameter.

As the unmarked viewpoint, facing competition from both Imparfait and Passé composé, Passé simple is quite fragile. The competition only increases, when Imparfait narratif challenges Passé simple in cases of narrative progression. The narrative complete event reading of the French IPF appeared quite late, in the beginning of the 20th century, but, as shown in section 5 , it is compatible with the invariant meaning of IPF in French. In narrative texts, a division of labour naturally arises between Imparfait narratif and Passé composé, such that the former is used when contemporaneity holds (typically with a coerced achievement predicate and a small assertion time), while the latter occurs with accomplishments and/or big assertion times.

In table 4, I have suggested that Passé composé has developed into an unmarked tense-aspect gram, compatible with any temporal configuration. This is an interesting point, suggested to me by Philippe Schlenker (p.c.). The idea and the relevant data definitely need further investigations. If Passé composé is a semantic default in contemporary French, we expect this gram to occur whenever the marked Imparfait is

9. Whether Passé simple exhibits incomplete event interpretations is not obvious (due to the strong competition from Imparfait), but it clearly combines with atelic predicates. 
inappropriate. Schlenker provides some highly intriguing data with a progressive, incomplete event context where Imparfait turns out to be unavailable for purely morphological reasons. The crucial point is that Imparfait seems to be replaced by a composite perfect in such environments. The relevant contrast is between the standard example (17) and (17'17'):

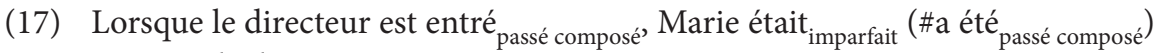
en train de danser.

When the director entered, Mary was dancing.

(17’) Bien que Marie ait été subjunctive passé composé (\#était imparfait $_{\text {' }}$ en train de danser lorsque le directeur était entré ${ }_{\text {composite past perfect }}$, elle ne sera pas licenciée. (no imperfective form in the subjunctive, and the past imperfective subjunctive is obsolete)

Even though Mary was dancing when the director entered, she was not fired.

(17”) Avoir été ${ }_{\text {composite perfect }}$ (\#était $_{\text {imparfait }}$ ) en train de danser lorsque le directeur est entré - quelle malchance!

(no imperfective form in the infinitive)

Having been dancing when the director entered - what bad luck!

\section{Conclusion}

In this paper, I have argued that some apparent similarities between imperfective viewpoints in Russian and French are quite accidental. Insights from traditional markedness theory, notably the idea that only the marked form should be accorded an invariant meaning, have here been explored in a framework of formal semantics, with some allusions also to optimality theory. Given the basic assumption that the Russian IPF is unmarked, while the French IPF is marked, I have shown how the different imperfective complete event readings arise in competition with other tense-aspect grams in a closed grammatical system. Crucially, while the Russian IPF is fully compatible, in the right context, with the perfective-like inclusion relation $e \subset t$, the marked Imparfait retains its meaning of contemporaneity even when it has a complete event interpretation in contexts of narrative progression. The so-called Imparfait narratif therefore encodes the condition $t=e$, and Imparfait tout court amounts to the improper inclusion relation $t \subseteq e$.

\section{References}

Beaver, D. \& Lee, H. 2003. Form-meaning asymmetries and bidirectional optimization. In J. Spenader, Eriksson, A. \& Ö. Dahl (eds.), Proceedings of the Stockholm Workshop on Variation within Optimality Theory, 138-148. Stockholm: Stockholm University. 
Bermel, N. 1997. Context and the Lexicon in the Development of Russian Aspect [Linguistics Vol. 129]. Berkeley CA: University of California Press.

Blutner, R. 2000. Some aspects of optimality in natural language interpretation. Journal of Semantics 17: 189-216.

Bohnemeyer, J. \& Swift, M. 2004. Event realization and default aspect. Linguistics and Philosophy 27: 263-296.

Bonomi, A. 2004. Semantical remarks on the progressive reading of the imperfective. Ms.

Breu, W. 1998. Sopostavlenie slavjanskogo glagol'nogo vida i vida romanskogo tipa (aorist:imperfekt:perfekt) na osnove vzaimodejstvija s leksikoj. In M. Chertkova, M. (ed), Tipologija vida, 88-99. Moscow: Jazyki russkoj kul'tury.

Ferreira, M. 2005. Event Quantification and Plurality. PhD dissertation, MIT.

Grønn, A. 2004. The Semantics and Pragmatics of the Russian Factual Imperfective. Dr. art. dissertation. Acta Humaniora Vol. 199. Oslo.

Grønn, A. 2007. Horn strategies and optimization in Russian aspect. In A. Benz, Ebert, C. \& van Rooij, R. (eds.), Proceedings of Language, Games, and Evolution, 17-24. Dublin: ESSLLI.

Grønn, A. 2008. Russian aspect as bidirectional optimization. In F. Marusic \& R. Zaucer (eds.), Studies in Formal Slavic Linguistics [Linguistik International Vol. 19], 121-137. Frankfurt: Peter Lang.

Heim, I. 1994. Comments on Abusch's theory of tense. In H. Kamp (ed.), Ellipsis, Tense and Questions, 143-170. Amsterdam: University of Amsterdam.

Hobæk Haff, M. 2005. L'Imparfait narratif - l'enfant terrible de l'univers aspectuo-temporel français. Révue Romane 40(1): 137-152.

Jayez, J. 1998. DRT et Imparfait. Un exemple de traitement formel du temps. In J. Moeschler (ed..), Le temps des événements, 123-154. Paris: Kimé.

Jayez, J. 1999. Imperfectivity and progressivity: The French imparfait. InT. Matthews \& D. Strolovitch (eds.), Proceedings of Semantics and Linguistic Theory IX, 145-162. Ithaka NY: Cornell University Press.

Kamp, H. 2001. The importance of presupposition. In C. Rohrer, A. Rossdeutscher \& H. Kamp (eds.), Linguistic Form and its Computation, 207-254. Stanford CA: CSU Publications.

Kamp, H. \& Rohrer, C. 1983. Tense in texts. In R. Bäuerle, C. Schwartze \& A. von Stechow (eds.), Meaning, Use, and Interpretation of Language, 250-269. Berlin: de Gruyter.

Klein, W. 1995. A time-relational analysis of Russian aspect. Language 71: 669-695.

Smith, C.S. 1997. The Parameter of Aspect. (2nd edn). Dordrecht: Kluwer.

von Stechow, A. 1995. On the proper treatment of tense. In T. Galloway \& M. Simons (eds.), Proceedings of Semantics and Linguistic Theory V, 362-386. Ithaka NY: Cornell University Press. 
